\title{
Proteomic profiling of cardiomyopathic tissue from the aged $m d x$ model of Duchenne muscular dystrophy reveals a drastic decrease in laminin, nidogen and annexin
}

\author{
Ashling Holland ${ }^{1}$, Paul Dowling ${ }^{2}$, Margit Zweyer $^{3}$, Dieter Swandulla ${ }^{3}$, Michael Henry ${ }^{2}$, \\ Martin Clynes ${ }^{2}$ and Kay Ohlendieck ${ }^{1}$ \\ ${ }^{1}$ Department of Biology, National University of Ireland, Maynooth, Ireland \\ ${ }^{2}$ National Institute for Cellular Biotechnology, Dublin City University, Dublin, Ireland \\ ${ }^{3}$ Department of Physiology II, University of Bonn, Bonn, Germany
}

\begin{abstract}
The majority of patients afflicted with Duchenne muscular dystrophy develop cardiomyopathic complications, warranting large-scale proteomic studies of global cardiac changes for the identification of new protein markers of dystrophinopathy. The aged heart from the X-linked dystrophic $m d x$ mouse has been shown to exhibit distinct pathological aspects of cardiomyopathy. In order to establish age-related alterations in the proteome of dystrophin-deficient hearts, cardiomyopathic tissue from young versus aged $m d x$ mice was examined by label-free LC-MS/MS. Significant age-dependent alterations were established for 67 proteins, of which 28 proteins were shown to exhibit a lower abundance and 39 proteins were found to be increased in their expression levels. Drastic changes were demonstrated for 17 proteins, including increases in Ig chains and transferrin, and drastic decreases in laminin, nidogen and annexin. An immunblotting survey of young and old wild-type versus $m d x$ hearts confirmed these proteomic findings and illustrated the effects of natural aging versus dystrophin deficiency. These proteome-wide alterations suggest a disintegration of the basal lamina structure and cytoskeletal network in dystrophin-deficient cardiac fibres, increased levels of antibodies in a potential autoimmune reaction of the degenerating heart, compensatory binding of excess iron and a general perturbation of metabolic pathways in dystrophy-associated cardiomyopathy.
\end{abstract}

Keywords:

Animal proteomics / Annexin / Cardiomyopathy / Laminin / Muscular dystrophy / Nidogen

\section{Introduction}

Duchenne muscular dystrophy is the most frequent neuromuscular disorder in humans and is characterised by the primary deficiency in the membrane cytoskeletal protein dystrophin [1]. Absence of the Dp427 isoform of dystrophin

\footnotetext{
Correspondence: Dr. Kay Ohlendieck, Professor and Chair, Department of Biology, National University of Ireland, Maynooth, Co. Kildare, Ireland

E-mail: kay.ohlendieck@nuim.ie

Fax: +353-1-708-3845
}

Abbreviation: $\boldsymbol{m d x}$, muscular dystrophy $\mathrm{x}$-linked
Received: December 20, 2012

Revised: April 11, 2013

Accepted: April 24, 2013 triggers a significant reduction in a number of sarcolemmal glycoproteins and causes a variety of downstream abnormalities in cell signalling, excitation-contraction coupling and ion homeostasis, as well as enhanced proteolytic destruction of muscle-associated proteins [2]. Disintegration of sarcolemmal integrity renders dystrophin-deficient fibres more susceptible to necrosis and eventually causes severe muscle wasting [3]. Importantly, cardiac dysfunction is a common clinical manifestation in neuromuscular disorders [4], particularly in hereditary muscular dystrophies [5]. During the second decade of life, the majority of patients afflicted with $\mathrm{X}$-linked muscular dystrophy show serious cardiac abnormalities [6], including cardiomyopathy, regional wall abnormalities and cardiac dysrhythmia [7]. 
Since the age of onset of cardiomyopathy in dystrophic children varies considerably and because skeletal muscle weakness and heart disease do not correlate, cellular factors other than dystrophin deficiency are believed to contribute to cardiomyopathy [8]. Overt cardiomyopathy drastically increases with age. More than $80 \%$ of teenage boys with muscular dystrophy show abnormal systolic function, resulting in fatal cardiac complications in a large number of cases [9]. Pathological hallmarks of cellular changes in muscular dystrophy-associated cardiomyopathy include interstitial inflammation, fatty tissue replacement, fibrosis and surface membrane degradation of cardiac tissue [10]. Since dystrophin-deficient cardiac fibres have only a limited regenerative capacity, the gradual replacement of cardiac fibres by non-contractile tissue results in progressive functional decline of the dystrophic heart [6].

Previous proteomic investigations of dystrophin-deficient muscle tissues have focused on mildly affected extraocular muscle, moderately necrotic limb muscles and severely dystrophic diaphragm muscle from the $m d x$ mouse $[2,11,12]$, an established animal model of Duchenne muscular dystrophy [13]. With respect to cardiac muscle, proteomic profiling of the immunoprecipitated dystrophin complex has established potential new binding partners of cardiac Dp427 [14] and metabolomic and proteomic studies have established the diverse effects of dystrophin deficiency on 9-month-old dystrophic heart tissue $[15,16]$. Importantly, the natural aging process itself is a major risk factor for cardiovascular disease. Intrinsic cardiac aging is associated with ventricular hypertrophy, increased fibrosis, atrial fibrillation and decreased maximal contractile capacity [17].

This makes the determination of protein changes in the senescent mouse model of severe muscular dystrophyassociated cardiomyopathy a crucial undertaking for the characterisation of this naturally occurring genetic animal model. Proteomic studies of the aging rodent heart have established changes in the concentration of metabolic enzymes, as well as components of cell signalling, the immune response, oxidative stress and structural support [18-20]. In analogy to these investigations of normal heart tissues during aging, this proteomic study has determined changes from 7-wk-old to 20-month-old $m d x$ hearts that lack dystrophin. Aged dystrophic hearts clearly exhibited a generally perturbed protein expression pattern with drastic changes in cardiac proteins involved in basal lamina stabilisation, cytoskeletal organisation, iron binding, antibody response, fibre contraction and energy metabolism.

\section{Materials and methods}

\subsection{Materials}

Analytical grade chemicals and materials used for the MSbased proteomic profiling of dystrophic hearts were obtained from Amersham Biosciences/GE Healthcare (Little Chalfont,
Buckinghamshire, UK) and BioRad Laboratories (HemelHempstead, Hertfordshire, UK). Sequencing grade modified trypsin and Lys-C were from Promega (Madison, WI, USA). Chemiluminescence substrate and protease inhibitors were purchased from Roche Diagnostics (Mannheim, Germany). Whatman NC transfer membranes were from Invitrogen (Carlsbad, CA, USA). Primary antibodies were purchased from Abcam, Cambridge, UK (ab41803 to annexin; ab34830 to malate dehydrogenase; ab110330 to pyruvate dehydrogenase; ab71440 to aconitase; ab43176 to ATP synthase; ab9033 to transferrin; ab14734 to VDAC-1; ab14511 to nidogen) and Sigma Chemical Company, Dorset, UK (L9393 to laminin). Secondary peroxidase-conjugated secondary antibodies were obtained from Chemicon International (Temecula, CA, USA). All other chemicals were purchased from Sigma Chemical Company (Dorest, UK).

\subsection{X-linked dystrophic $m d x$ mouse model}

Duchenne muscular dystrophy is caused by primary abnormalities in the dystrophin gene of the human X-chromosome. In analogy, the established $m d x$ animal model is missing the full-length dystrophin isoform Dp427 due to a point mutation in exon 23 [13]. In order to study global age-related changes in the dystrophic heart proteome, cardiac muscle tissue from 7-wk-old $m d x$ mice, 20-month-old $m d x$ mice, 7-wk-old control C57 mice and 20-month-old control C57 mice were obtained from the animal facility of the University of Bonn [21]. Mice were kept under standard conditions and all procedures were carried out in accordance with Irish and German guidelines on the use of animals for scientific experiments. Animals were sacrificed by cervical dislocation and their hearts immediately quick-frozen in liquid nitrogen.

\subsection{Preparation of tissue extracts from normal and dystrophic heart muscle}

The preparation of $m d x$ cardiac tissue was carried out by a previously optimised method [16]. Hearts from 7-wk-old $m d x$ mice $(n=4)$ and 20-month-old $m d x$ mice $(n=4)$, as well as age-matched normal mice, were washed with PBS to remove excess blood and then cardiac tissue $(100 \mathrm{mg})$ was finely chopped and homogenised in 0.5 M HEPES, pH 7.4, $200 \mathrm{mM}$ EGTA, 10\% w/v sucrose, $3 \mathrm{mM}$ magnesium chloride, and $0.1 \% \mathrm{w} / \mathrm{v}$ sodium azide, using a hand held Kontes PelletPestle Motor homogeniser. To prevent proteolytic degradation of sensitive cardiac muscle proteins, the buffer was supplemented with a protease inhibitor cocktail [22]. Cardiac tissue samples were ground into a fine powder in liquid nitrogen using a pestle and mortar. The tissue powder was re-suspended in lysis buffer $(9.5 \mathrm{M}$ urea, 2\% CHAPS, $0.8 \%$ ampholytes $\mathrm{pH} 3-10,1 \%$ DTT and a protease inhibitor cocktail) at a ratio of $1: 10 \mathrm{w} / \mathrm{v}$. Crude extracts were gently shaken at $4^{\circ} \mathrm{C}$ for $2 \mathrm{~h}$ using a Thermomixer from Eppendorf 
(Hamburg, Germany). Following centrifugation at $4^{\circ} \mathrm{C}$ for $20 \mathrm{~min}$ at $14000 \times \mathrm{g}$, the supernatant fractions from normal and dystrophic preparations were removed and used for the comparative gel electrophoretic separation of the urea-soluble protein repertoire from heart muscle.

\subsection{Sample preparation for label-free LC-MS/MS analysis}

Crude cardiac samples were pre-treated with the Ready Prep 2D clean up kit from BioRad Laboratories. The resulting protein pellets were re-suspended in label-free solubilisation buffer, consisting of $6 \mathrm{M}$ urea, $2 \mathrm{M}$ thiourea and $10 \mathrm{mM}$ Tris, pH 8.0 in LC-MS grade water [23,24]. Protein suspensions were vortexed, sonicated and centrifuged to ensure pellets were fully re-suspended and then their protein concentration was determined [22]. For label-free MS analysis, volumes were kept to a minimum and initially equalised using label-free solubilisation buffer. Samples were reduced for $30 \mathrm{~min}$ with $10 \mathrm{mM}$ DTT and alkylated for $20 \mathrm{~min}$ in the dark with $25 \mathrm{mM}$ iodoacetamide in $50 \mathrm{mM}$ ammonium bicarbonate. The initial proteolytic digestion was carried out with sequencing grade Lys-C at a ratio of $1: 100$ (protease/protein) for $4 \mathrm{~h}$ at $37^{\circ} \mathrm{C}$. The samples were subsequently diluted with four times the initial sample volume in $50 \mathrm{mM}$ ammonium bicarbonate. A second digestion step was performed with sequencing grade trypsin at a ratio of $1: 25$ (protease/protein) overnight at $37^{\circ} \mathrm{C}$. Prior to MS analysis, the digested protein preparations were diluted $3: 1 \mathrm{v} / \mathrm{v}$ with $2 \%$ TFA in $20 \% \mathrm{ACN}$, vortexed and sonicated to ensure an even suspension.

\subsection{Label-free LC-MS/MS analysis}

An Ultimate 3000 nanoLC system (Dionex) coupled to a an LTQ Orbitrap XL mass spectrometrer from Thermo Fisher Scientific (Dublin, Ireland) was employed for nano LCMS/MS analysis in the Proteomics Facility of the NICB, Dublin City University, as previously described by Meleady et al. $[23,24]$. Digested peptide mixtures $(5 \mu \mathrm{L}$ volume) were loaded onto a C18 trap column (C18 PepMap, $300 \mu \mathrm{m}$ id $\times$ $5 \mathrm{~mm}, 5 \mu \mathrm{m}$ particle size, $100 \AA \AA$ pore size; Dionex). Desalting was carried out at a flow rate of $25 \mu \mathrm{L} / \mathrm{min}$ in $0.1 \%$ TFA for $10 \mathrm{~min}$. The trap column was switched on-line with an analytical PepMap C18 column (75 $\mu \mathrm{m}$ id $\times 250 \mathrm{~mm}, 3 \mu \mathrm{m}$ particle and $100 \AA$ pore size; Dionex). Peptides generated from cardiac proteins were eluted with the following binary gradients: solvent A (2\% ACN and $0.1 \%$ formic acid in LC-MS grade water) and $0-25 \%$ solvent B $(80 \% \mathrm{ACN}$ and $0.08 \%$ formic acid in LC-MS grade water) for $240 \mathrm{~min}$ and $25-50 \%$ solvent $\mathrm{B}$ for a further $60 \mathrm{~min}$. The column flow rate was set to $350 \mathrm{~nL} / \mathrm{min}$ [24]. Data were acquired with Xcalibur software, version 2.0.7 (Thermo Fisher Scientific). The MS apparatus was operated in data-dependent mode and externally calibrated. Survey MS scans were acquired in the Orbitrap in the $400-1800 \mathrm{~m} / z$ range with the resolution set to a value of 30000 at $\mathrm{m} / z 400$ and lock mass set to $445.120025 \mathrm{u}$. CID fragmentation was carried out in the linear ion trap with up to seven of the most intense ions $(1+, 2+$ and $3+)$ per scan [23]. Within $40 \mathrm{~s}$, a dynamic exclusion window was applied. A normalised collision energy of $35 \%$, an isolation window of $3 \mathrm{~m} / \mathrm{z}$ and one microscan were used to collect suitable tandem mass spectra $[23,24]$.

\subsection{Quantitative profiling by label-free LC-MS/MS analysis}

Progenesis label-free LC-MS software version 3.1 from NonLinear Dynamics (Newcastle upon Tyne, UK) was used to process the raw data generated from LC-MS/MS analysis. Data alignment was based on the LC retention time of each sample, allowing for any drift in retention time given and adjusted retention time for all runs in the analysis [23]. A reference run was established with the sample run that yielded most features (i.e. peptide ions). The retention times of all of the other runs were aligned to this reference run and peak intensities were then normalised. Prior to exporting the MS/MS output files to MASCOT (www.matrixscience.com) for protein identification, a number of criteria were employed to filter the data. These data included (i) peptide features with ANOVA $<0.05$ between experimental groups, (ii) mass peaks (features) with charge states from $+1,+2,+3$, and (iii) greater than one isotope per peptide [23]. A MASCOT generic file was generated from all exported MS/MS spectra from Progenesis software. The MASCOT generic file was used for peptide identification with MASCOT (version 2.2) and searched against the UniProtKB-SwissProt database (downloaded in April 2012) with 16521 proteins (taxonomy: Mus musculus). The following search parameters were used for protein identification: (i) MS/MS mass tolerance set at $0.5 \mathrm{Da}$, (ii) peptide mass tolerance set to $10 \mathrm{ppm}$, (iii) carbamidomethylation set as a fixed modification, (iv) up to two missed cleavages were allowed and (v) methionine oxidation set as a variable modification. For further consideration and re-importation back into Progenesis LC-MS software for further analysis, only peptides with ion scores of 40 and above were chosen [24]. Importantly, the following criteria were applied to assign a heart-associated protein as properly identified: (i) an ANOVA score between experimental groups of $\leq 0.05$, (ii) proteins with $\geq 2$ peptides matched and (iii) a MASCOT score $>40[23,24]$.

\subsection{Verification of key proteomic hits by immunoblotting}

In order to confirm altered concentration levels of distinct muscle proteins revealed from label-free LC-MS/MS analysis, immunoblotting was employed. 1DE and immunoblotting were carried out by a previously described method [25]. Electrophoretic separation of cardiac proteins 
from 7-wk-old normal versus $m d x$ mice and 20-month-old normal versus $m d x$ mice was performed with standard $10 \%$ PAGE gels, followed by wet transfer at $100 \mathrm{~V}$ for $70 \mathrm{~min}$ to Whatman Protan NC sheets in a Transblot Cell from BioRad Laboratories. Membranes were blocked for $1 \mathrm{~h}$ with a milk protein solution (consisting of $5 \% \mathrm{w} / \mathrm{v}$ fat-free milk powder in $10 \% \mathrm{PBS}$ ) to prevent non-specific antibody binding. NC sheets were incubated with sufficiently diluted primary antibodies to a variety of identified cardiac proteins for $3 \mathrm{~h}$ with gentle agitation at $4^{\circ} \mathrm{C}$. Following several washing steps, membranes were incubated for $1 \mathrm{~h}$ at $4^{\circ} \mathrm{C}$ with secondary antibodies. Peroxidase-conjugated antibodies were sufficiently diluted in blocking solution to prevent non-specific binding. Immuno-decorated protein bands were then visualised on washed membranes by the ECL method. Densitometric scanning and evaluation of immunoblots was performed with a HP PSC-2355 scanner and ImageJ (NIH, USA) and GraphPad Prism (San Diego, CA, USA) software.

\section{Results}

Proteomic profiling of 7-wk-old versus 20-month-old $m d x$ hearts was carried out to determine the extent of age-related protein changes in muscular dystrophy-associated cardiomyopathy. Following the determination of protein alterations by a label-free LC-MS/MS approach, key proteomic findings were verified by immunblotting of young and aged wild-type versus age-matched $m d x$ hearts to differentiate between the effects of the natural aging process versus the lack of dystrophin in the $m d x$ heart.

\subsection{Proteomic profiling of 7-wk-old heart tissue from normal versus $m d x$ mice}

A label-free LC-MS analysis of 7-wk-old normal cardiac samples versus age-matched $m d x$ samples was used to establish differences between unaffected and dystrophin-deficient heart tissue. The comparative proteomic profiling study revealed moderate changes in 20 heart-associated proteins (Table 1), agreeing with the mild cardiomyopathic phenotype in young dystrophic mice. An increased abundance was shown for actin, biglycan, protein disulphide isomerase, calreticulin, the mitochondrial enzymes succinyl-CoA:3ketoacid-coenzyme A transferase, 2-oxoglutarate dehydrogenae and isocitrate dehydrogenase, as well as the glycolytic enzyme phosphofructokinase. In contrast, slightly decreased levels were found for troponin TnT, aortic actin, seleniumbinding protein and glyceraldehyde-3-phosphate dehydrogenase, as well as the mitochondrial enzymes succinylCoA ligase, methylmalonate-semialdehyde dehydrogenase, 3-hydroxyacyl-CoA dehydrogenase, 2,4-dienoyl-CoA reductase, 3-ketoacyl-CoA thiolase and glutamate dehydrogenase.

\subsection{Label-free LC-MS/MS analysis of the aged dystrophin-deficient $\boldsymbol{m d x}$ heart}

Since aging drastically accelerates the dystrophy-related cardiomyopathic phenotype of the $m d x$ model of Duchenne muscular dystrophy, label-free LC-MS/MS analysis of 7-wkold versus 20 -month-old $m d x$ hearts was performed to determine global changes in dystrophin-deficient cardiac tissue. Significant changes were found in 67 proteins, whereby 39 proteins were shown to be increased in abundance and a decreased expression was determined for 28 proteins (Table 2). Besides moderate changes in 50 heart-associated proteins, positive or negative alterations above a 2.5-fold change were shown in 17 proteins. Proteins with a drastically increased density were identified as various Ig chains, mitochondrial beta-hydroxybutyrate dehydrogenase, ferritin light and heavy chain, catalase and transferrin. Considerable reductions were shown for lamin, laminin, myosin light chain, nidogen, vimentin and long chain fatty acid ligase. A variety of cardiac proteins were marginally affected in a differential manner and MS analysis identified them as proteins involved in muscle contraction, mitochondrial metabolism, glycolysis, ion handling, cytoskeletal organisation and the cellular stress response.

\subsection{Immunoblot analysis of aged normal versus aged $m d x$ heart}

Since the label-free LC-MS/MS analysis shown here has focused on age-related effects in the $m d x$ heart, immunoblotting was used to verify key proteomic findings and also to compare the expression levels of identified proteins in normal versus dystrophic preparations. Figures 1 and 2 show the immunoblot survey of 7-wk-old normal hearts, 7-wk-old $m d x$ hearts, 20-month-old normal hearts and 20-month-old $m d x$ hearts. Silver staining of crude tissue extracts from the four different heart preparations did not show extensive differences in their overall 1D banding pattern following SDSPAGE analysis, but slight variations in the intensity of individual bands (Fig. 1A). A variety of antibodies were evaluated and representative immunoblots with reliable staining patterns are shown in Figs. 1 and 2. The increase in transferrin was confirmed by immunoblotting, although differences were not found to be statistically significant (Fig. 1B). The drastic decrease in the expression levels of laminin, nidogen and annexin during aging of the $m d x$ heart were found to be statistically significant (Fig. 1C, E, F). Labelling with specific antibodies to these three cardiac proteins clearly verified the proteomic findings listed in Table 2. Importantly, while the concentration of laminin, nidogen and annexin increased during natural aging, the deficiency in dystrophin caused the opposite effect (Fig. 1C, E, F). No significant alterations in the expression of ATP synthase were found (Fig. 1D).

A previous gel-based study of the dystrophic heart has shown reduced levels of many mitochondrial and metabolic 
Table 1. List of changed proteins in 7-wk-old $m d x$ heart tissue versus age-matched normal controls as determined by label-free MS/MS analysis

\begin{tabular}{|c|c|c|c|c|c|}
\hline Accession number & Protein name & Peptides & Score & Anova & Fold change \\
\hline P68134 & Actin, alpha, muscle & 3 & 141.67 & 0.03 & 2.30 \\
\hline P28653 & Biglycan & 2 & 104.16 & 0.02 & 1.77 \\
\hline P09103 & Protein disulphide-isomerase & 3 & 127.77 & 0.01 & 1.51 \\
\hline P27773 & Protein disulphide-isomerase A3 & 3 & 145.22 & 0.02 & 1.47 \\
\hline Q9D0K2 & $\begin{array}{l}\text { Succinyl-CoA:3-ketoacid-coenzyme A } \\
\text { transferase 1, mitochondrial }\end{array}$ & 2 & 143.54 & 0.02 & 1.43 \\
\hline Q8BFZ3 & Beta-actin-like protein 2 & 2 & 93.12 & 0.05 & 1.41 \\
\hline Q60597 & 2-Oxoglutarate dehydrogenase, mitochondrial & 2 & 97.42 & 0.02 & 1.38 \\
\hline P14211 & Calreticulin & 2 & 90.7 & 3.71E-03 & 1.29 \\
\hline P54071 & $\begin{array}{l}\text { Isocitrate dehydrogenase [NADP], } \\
\text { mitochondrial }\end{array}$ & 3 & 215.87 & 0.03 & 1.28 \\
\hline P47857 & 6-Phosphofructokinase, muscle type & 2 & 138.74 & 0.03 & 1.25 \\
\hline P26443 & Glutamate dehydrogenase 1, mitochondrial & 2 & 102.33 & 0.02 & -1.23 \\
\hline Q8BWT1 & 3-Ketoacyl-CoA thiolase, mitochondrial & 3 & 220.83 & 0.02 & -1.24 \\
\hline P16858 & Glyceraldehyde-3-phosphate dehydrogenase & 3 & 245.05 & 0.01 & -1.25 \\
\hline P17563 & Selenium-binding protein 1 & 3 & 144.51 & 0.02 & -1.36 \\
\hline Q9CQ62 & 2,4-Dienoyl-CoA reductase, mitochondrial & 2 & 147.96 & 8.71E-03 & -1.38 \\
\hline 008756 & 3-Hydroxyacyl-CoA dehydrogenase type-2 & 2 & 154.83 & 0.03 & -1.41 \\
\hline Q9EQ20 & $\begin{array}{l}\text { Methylmalonate-semialdehyde dehydrogenase } \\
\text { [acylating], mitochondrial }\end{array}$ & 4 & 198.45 & $2.62 \mathrm{E}-03$ & -1.43 \\
\hline Q9Z219 & $\begin{array}{l}\text { Succinyl-CoA ligase [ADP-forming] subunit } \\
\text { beta, mitochondrial }\end{array}$ & 3 & 152.4 & $7.12 \mathrm{E}-03$ & -1.49 \\
\hline P62737 & Actin, aortic smooth muscle & 2 & 95.23 & $1.12 \mathrm{E}-03$ & -1.62 \\
\hline P50752 & Troponin T, cardiac muscle & 2 & 101.51 & 0.01 & -1.68 \\
\hline
\end{tabular}

proteins [16]. To correlate the findings from our aging study to these previously established alterations in the $m d x$ heart, antibody labelling of crucial metabolic enzymes and mitochondrial markers was employed. Immunoblotting of pyruvate dehydrogenase, aconitase and malate dehydrogenase demonstrated a significant reduction of these metabolic enzymes during aging of cardiac muscle from the $m d x$ mouse (Fig. 2AC). The mitochondrial marker protein VDAC1 also showed reduced levels in 20-month-old $m d x$ hearts as compared to younger dystrophic hearts (Fig. 2D). The analysis of antibody labelling to lamin, myosin light chain and vimentin did not result in significant differences between young versus aged $m d x$ preparations (not shown).

\section{Discussion}

A variety of novel pharmacological, cellular and genetic approaches are currently tested to counteract the symptoms of dystrophinopathies [26], including the treatment of cardiomyopathic complications [6]. To better monitor the therapeutic success of experimental treatments and evaluate potential side effects, as well as generally improve diagnostic procedures, there is an urgent need for superior biomarkers of X-linked muscular dystrophy and associated cardiomyopathy. Experimental models of Duchenne muscular dystrophy exhibit many of the symptoms of cardiovascular disease seen in patients and are therefore frequently employed in pre-clinical investigations [27]. Dystrophin-deficient tissues are widely used as drug testing systems, including $m d x$ heart preparations [28]. The $m d x$ mouse is missing dystrophin due to a point mutation in exon 23 [13] and shows many secondary abnormalities of the dystrophic phenotype [29]. Deficiency in cardiac dystrophin is associated with a variety of biochemical, physiological and cellular abnormalities, including a reduction in dystrophin-associated glycoproteins, disturbed $\mathrm{Ca}^{2+}$ signaling, a substantial decrease in luminal $\mathrm{Ca}^{2+}$-buffering proteins, amplification of ROS-generating pathways, broad infiltration of inflammatory cells, greater amounts of adipose tissue, fibre necrosis and fibrosis, as well as tachycardia and abnormal excitation-contraction-relaxation cycles in the $m d x$ heart [30-38].

Since aging appears to accelerate the degenerative phenotype of the $m d x$ heart [39-41], we have applied MS-based proteomics to study the altered protein expression profile of 7-wk-old versus 20-month-old dystrophic hearts. Both, the subcellular localisation and the composition of the cardiac dystrophin-glycoprotein complex differs from skeletal muscle [14, 42], which might explain how the heart and skeletal muscle tissue are differently affected in dystrophinopathy. The proteomic findings presented here indicate aging-associated alterations in components involved in the contraction-relaxation cycle, bioenergetics, iron binding, nuclear integrity, extracellular matrix organisation, cytoskeletal maintenance and the cellular stress response. In addition, high concentrations of antibodies were found in cardiac $m d x$ preparations by MS analysis. This agrees with 
Table 2. List of changed proteins in aging $m d x$ heart tissue as determined by label-free MS/MS analysis

\begin{tabular}{|c|c|c|c|c|c|}
\hline Accession number & Protein name & Peptides & Score & Anova & Fold change \\
\hline P01864 & Ig gamma-2A chain, $C$ region & 4 & 238.19 & $1.43 E-03$ & 19.59 \\
\hline Q80XN0 & $\begin{array}{l}\text { D-beta-hydroxybutyrate dehydrogenase, } \\
\text { mitochondrial }\end{array}$ & 3 & 201.56 & $7.48 \mathrm{E}-04$ & 10.63 \\
\hline P01867 & Ig gamma-2B chain, $\mathrm{C}$ region & 3 & 130.75 & $1.59 \mathrm{E}-03$ & 9.32 \\
\hline P01872 & Ig mu chain, $\mathrm{C}$ region & 2 & 129.15 & $5.20 \mathrm{E}-03$ & 8.83 \\
\hline P01837 & Ig kappa chain, $\mathrm{C}$ region & 3 & 192.25 & 2.37E-03 & 4.98 \\
\hline P29391 & Ferritin light chain 1 & 4 & 248.68 & $9.40 \mathrm{E}-04$ & 4.54 \\
\hline P24270 & Catalase & 2 & 112.04 & 0.03 & 2.9 \\
\hline P09528 & Ferritin heavy chain & 4 & 281.25 & $1.81 \mathrm{E}-03$ & 2.82 \\
\hline Q921I1 & Transferrin & 2 & 103.14 & 0.03 & 2.56 \\
\hline P15626 & GSH transferase & 6 & 340.24 & $9.70 \mathrm{E}-04$ & 2.14 \\
\hline Q9DBJ1 & Phosphoglycerate mutase 1 & 3 & 154.49 & 0.02 & 1.91 \\
\hline Q9DCM2 & GSH transferase & 2 & 128.36 & $5.24 \mathrm{E}-03$ & 1.86 \\
\hline P54071 & $\begin{array}{l}\text { Isocitrate dehydrogenase [NADP], } \\
\text { mitochondrial }\end{array}$ & 23 & 2050.16 & $5.98 \mathrm{E}-04$ & 1.85 \\
\hline Q6P8J7 & Creatine kinase S-type, mitochondrial & 2 & 137.95 & 0.04 & 1.79 \\
\hline P17742 & Peptidyl-prolyl cis-trans isomerase A & 3 & 186.4 & 1.57E-03 & 1.76 \\
\hline P68134 & Actin, alpha & 4 & 273.36 & $3.98 \mathrm{E}-03$ & 1.75 \\
\hline Q9JHI5 & Isovaleryl-CoA dehydrogenase, mitochondrial & 8 & 572.22 & 8.73E-04 & 1.68 \\
\hline P47738 & Aldehyde dehydrogenase, mitochondrial & 4 & 213.46 & $1.91 \mathrm{E}-03$ & 1.67 \\
\hline P51174 & $\begin{array}{l}\text { Long-chain specific acyl-CoA dehydrogenase, } \\
\text { mitochondrial }\end{array}$ & 8 & 513.47 & $2.89 \mathrm{E}-03$ & 1.66 \\
\hline O70250 & Phosphoglycerate mutase 2 & 5 & 269.27 & 0.02 & 1.66 \\
\hline P10649 & GSH transferase & 7 & 472.38 & 0.01 & 1.65 \\
\hline P16125 & L-lactate dehydrogenase B chain & 2 & 199.75 & 7.91E-04 & 1.58 \\
\hline P26041 & Moesin & 3 & 134.23 & $1.00 \mathrm{E}-02$ & 1.58 \\
\hline P19157 & GSH transferase & 2 & 171.48 & 0.03 & 1.56 \\
\hline P04247 & Myoglobin & 8 & 971.05 & 4.14E-03 & 1.54 \\
\hline P05064 & Fructose-bisphosphate aldolase A & 2 & 89.51 & 0.04 & 1.54 \\
\hline P62737 & Actin, aortic smooth muscle & 2 & 207.26 & $5.91 \mathrm{E}-03$ & 1.53 \\
\hline P62962 & Profilin-1 & 3 & 190.16 & $1.11 \mathrm{E}-03$ & 1.46 \\
\hline P60710 & Actin, cytoplasmic 1 & 4 & 256.28 & 8.91E-03 & 1.45 \\
\hline O70468 & Myosin-binding protein C, cardiac-type & 3 & 190.42 & 0.01 & 1.45 \\
\hline P56565 & Protein S100-A1 & 2 & 174.38 & $3.90 \mathrm{E}-05$ & 1.45 \\
\hline Q9D0K2 & $\begin{array}{l}\text { Succinyl-CoA:3-ketoacid-coenzyme A } \\
\text { transferase 1, mitochondrial }\end{array}$ & 3 & 333.51 & 7.79E-03 & 1.44 \\
\hline Q60597 & 2-Oxoglutarate dehydrogenase, mitochondrial & 3 & 156.25 & 6.77E-03 & 1.41 \\
\hline P45376 & Aldose reductase & 3 & 177.39 & 0.02 & 1.38 \\
\hline Q99KI0 & Aconitate hydratase, mitochondrial & 17 & 1228.3 & $5.62 \mathrm{E}-05$ & 1.36 \\
\hline P05201 & Aspartate aminotransferase, cytoplasmic & 7 & 504.11 & $2.22 \mathrm{E}-03$ & 1.35 \\
\hline P06745 & Glucose-6-phosphate isomerase & 4 & 346.71 & 4.29E-05 & 1.35 \\
\hline P17751 & Triosephosphate isomerase & 2 & 116.97 & 0.02 & 1.29 \\
\hline Q8QZT1 & Acetyl-CoA acetyltransferase, mitochondrial & 3 & 164.07 & $6.03 \mathrm{E}-03$ & 1.27 \\
\hline P52503 & $\begin{array}{l}\text { NADH dehydrogenase [ubiquinone] } \\
\text { iron-sulphur protein } 6, \text { mitochondrial }\end{array}$ & 2 & 137.35 & 0.01 & -1.23 \\
\hline P62631 & Elongation factor 1-alpha 2 & 4 & 296.15 & 0.04 & -1.26 \\
\hline Q9D3D9 & ATP synthase subunit delta, mitochondrial & 2 & 185.13 & 0.03 & -1.37 \\
\hline Q9CQA3 & $\begin{array}{l}\text { Succinate dehydrogenase [ubiquinone] } \\
\text { iron-sulphur subunit, mitochondrial }\end{array}$ & 3 & 201.11 & 0.05 & -1.4 \\
\hline P56480 & ATP synthase subunit beta, mitochondrial & 10 & 854.08 & 0.04 & -1.42 \\
\hline P10126 & Elongation factor 1-alpha 1 & 4 & 232.69 & 0.03 & -1.47 \\
\hline P63038 & 60 kDa HSP, mitochondrial & 4 & 280.95 & 0.02 & -1.55 \\
\hline P57776 & Elongation factor 1-delta & 2 & 111.73 & 0.03 & -1.6 \\
\hline P68372 & Tubulin beta-4B chain & 2 & 102.84 & 0.05 & -1.72 \\
\hline Q9D855 & Cytochrome b-c1 complex, subunit 7 & 5 & 280 & 1.07E-03 & -1.76 \\
\hline P12787 & $\begin{array}{l}\text { Cytochrome c oxidase, subunit } 5 \mathrm{~A} \text {, } \\
\text { mitochondrial }\end{array}$ & 5 & 319.85 & 0.01 & -1.81 \\
\hline Q9CXZ1 & $\begin{array}{l}\text { NADH dehydrogenase [ubiquinone] } \\
\text { iron-sulphur protein 4, mitochondrial }\end{array}$ & 4 & 229.86 & 0.03 & -1.86 \\
\hline Q9DB15 & $39 S$ ribosomal protein L12, mitochondrial & 2 & 113.08 & 0.02 & -1.88 \\
\hline
\end{tabular}


Table 2. Continued

\begin{tabular}{|c|c|c|c|c|c|}
\hline Accession number & Protein name & Peptides & Score & Anova & Fold change \\
\hline P51667 & $\begin{array}{l}\text { Myosin regulatory light chain } 2 \text {, } \\
\text { ventricular/cardiac muscle isoform }\end{array}$ & 4 & 267.78 & 0.03 & -1.96 \\
\hline P14824 & Annexin A6 & 2 & 112.82 & 0.04 & -1.96 \\
\hline P97450 & ATP synthase-coupling factor 6 , mitochondrial & 5 & 403.38 & 0.03 & -2.05 \\
\hline P61979 & Heterogeneous nuclear ribonucleoprotein $\mathrm{K}$ & 2 & 96.7 & $5.93 \mathrm{E}-03$ & -2.05 \\
\hline Q9Z2I9 & $\begin{array}{l}\text { Succinyl-CoA ligase [ADP-forming] subunit } \\
\text { beta, mitochondrial }\end{array}$ & 3 & 172.2 & 0.03 & -2.07 \\
\hline P70670 & $\begin{array}{l}\text { Nascent polypeptide-associated complex } \\
\text { subunit alpha, muscle-specific form }\end{array}$ & 3 & 171.72 & 0.03 & -2.08 \\
\hline Q99020 & Heterogeneous nuclear ribonucleoprotein A/B & 2 & 102.84 & 2.43E-03 & -2.11 \\
\hline P48678 & Prelamin-A/C & 3 & 177.88 & 0.04 & -2.67 \\
\hline P41216 & Long-chain fatty acid-CoA ligase 1 & 2 & 120.37 & $2.85 \mathrm{E}-03$ & -2.77 \\
\hline P20152 & Vimentin & 3 & 146.1 & 0.05 & -3.04 \\
\hline P10493 & Nidogen-1 & 2 & 100.17 & $6.04 \mathrm{E}-03$ & -3.36 \\
\hline Q3THE2 & Myosin regulatory light chain 12B & 2 & 105.15 & $6.44 \mathrm{E}-03$ & -4.03 \\
\hline P02468 & Laminin subunit gamma-1 & 5 & 277.53 & 8.68E-04 & -4.22 \\
\hline P02469 & Laminin subunit beta-1 & 3 & 171.32 & $5.45 \mathrm{E}-04$ & -4.71 \\
\hline P14733 & Lamin-B1 & 2 & 100.13 & 0.01 & -12.91 \\
\hline
\end{tabular}

the general idea of autoimmune mechanisms being involved in the molecular pathogenesis of cardiomyopathy [43]. Possibly the deficiency in cardiac dystrophin leads to structural damage and tissue injury which in turn provokes autoimmunity or triggers infiltration of antibodies. Proteomic profiling of the dystrophin-deficient heart showed a drastic increase of antibodies during aging of the $m d x$ mouse. This finding suggests a possible role of autoimmunity in muscular dystrophyrelated cardiomyopathy or antibody penetration into muscle cells through leaky membranes. It is not known whether the increased antibody levels are a pathophysiological effect or a triggering factor of cardiomyopathy.

Other interesting proteins with elevated levels in the dystrophic heart are represented by transferrin, ferritin and GSH transferase. Since mammalian cells require sufficient iron levels for metabolic maintenance, transferrin levels are an important indicator of potential changes in iron absorption and usage [44]. Transferrin is an essential circulating protein that delivers iron to tissue proteins [45], thus changed levels of this transporter protein is indicative of disturbed cardiac iron homeostasis in muscular dystrophy. Another key player in iron metabolism is ferritin, a ubiquitous intracellular ironbinding protein [46]. Ferritins sequester and release iron in a highly regulated fashion, thereby serving the dual physiological functions of iron detoxification and iron reserve [47]. Its elevated level in the $m d x$ heart suggests that ferritin buffers against a potential iron overload in the dystrophic phenotype.

GSH transferase is a crucial catalyst in the GSH-dependent biotransformation of xenobiotics [48] and elevated levels therefore suggest increased stress levels in the $m d x$ heart. In skeletal and cardiac muscle, GSH transferases also form ion channels in intracellular membrane systems and have been shown to modulate the ryanodine receptor $\mathrm{Ca}^{2+}$-release channel [49]. Thus, a higher concentration of GSH transferases could also be a compensatory mechanism to counteract ab- normal $\mathrm{Ca}^{2+}$ handling in muscular dystrophy. The fact that increased protein oxidation by reactive-free radical species induces muscle cell damage in both Duchenne patients [50] and the $m d x$ mouse [51] and the establishment of altered GSH metabolism in oxidative damage [52], makes the proteomic identification of GSH transferase and catalase an interesting finding. As reviewed by Tidball and Wehling-Henricks [53], the collapse of the dystrophin-glycoprotein complex appears to disrupt the normal production of free radicals and thereby contributes to the pathophysiology of muscular dystrophies. This might be due to constitutive differences in free radical production and concomitant disruption of crucial signalling processes in contractile fibres and/or a shift in free radical production, which promotes cellular injury and contractile dysfunction [53]. With respect to the $m d x$ heart, changes in ROS and oxidative damage were shown to be involved in the molecular pathogenesis of cardiac dysfunction [54]. It is therefore possible that GSH transferase might be involved in an antioxidant response in the dystrophic heart. Increased catalase levels for the enhanced removal of hydrogen peroxide would also agree with this concept of an antioxidant mechanism in $m d x$ tissue. A recent study by Selsby [55] suggests that an elevated expression of catalase improves muscle function in $m d x$ mice, hence a high concentration of catalase could play a crucial role in decreasing cellular injury in the dystrophin-deficient myocardium.

Both proteomics and immunoblotting demonstrated differential expression levels of laminin, nidogen and annexin in normal versus dystrophic hearts at the two different ages studied. This indicates abnormalities in the extracellular matrix, basement membrane and cytoskeletal network of the dystrophin-deficient heart. Laminin is an essential component of the basement membrane and critical for the structural integrity of the extracellular matrix. Changes in laminin affect interactions between associated cells due to altered patterns 


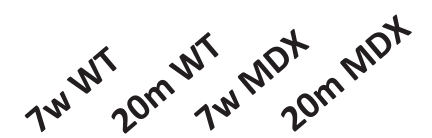

A Silver

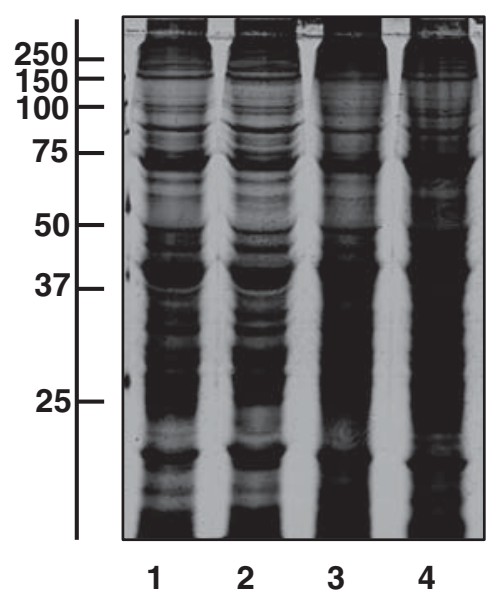

D ATP synthase
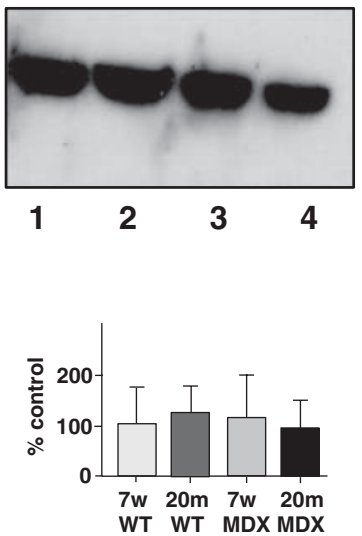

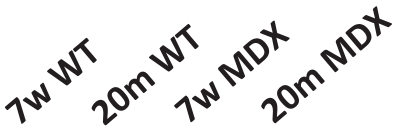

B Transferrin
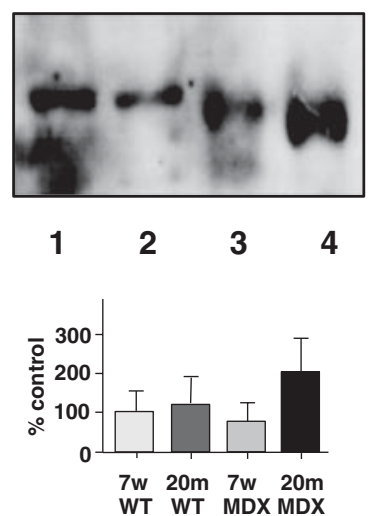

E Nidogen
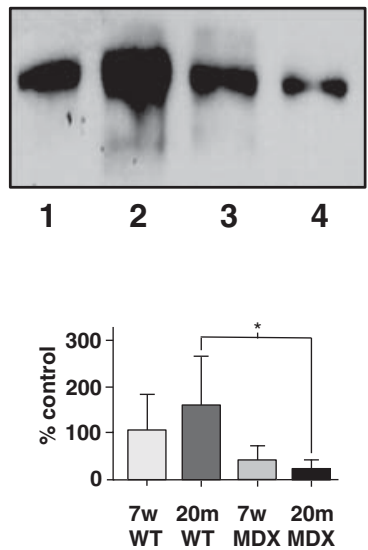

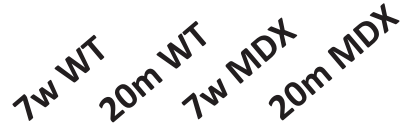

C Laminin
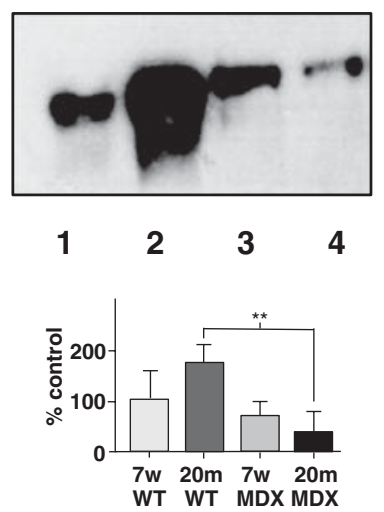

F Annexin
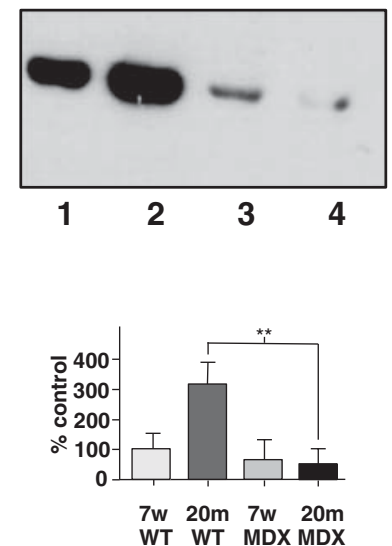

Figure 1. Gel electrophoretic analysis and immunoblotting survey of cardiac proteins in young versus aged normal and dystrophic mdx mice. A representative Silver-stained gel is shown in panel A. Corresponding immunoblots with expanded views illustrate immunodecorated bands (B-F). The immunoblot analysis of heart-associated proteins was performed with antibodies to transferrin (B), laminin (C), ATP synthase (D), nidogen (E) and annexin (F). Molecular mass standards (in kDa) are indicated on the left of panel A. Lanes 1 to 4 represent normal 7-wk-old hearts, normal 20-month-old hearts, 7-wk-old mdx hearts and 20-month-old mdx hearts, respectively. Underneath individual immunolots are shown graphical presentation of the statistical evaluation of immuno-decorations. The comparative blotting between 7-wk-old $m d x$ hearts and 20-month old $m d x$ hearts was statistically evaluated using an unpaired Student's $t$-test $(n=5$; $\left.{ }^{*} p<0.05 ;{ }^{*} p<0.01\right)$. The concentration of laminin, nidogen and annexin was found to be significantly different between young and old $m d x$ hearts.

of adhesion, differentiation and migration [56]. An abnormal laminin function is clearly involved in altered cell-matrix interactions in muscle disease [57]. Laminin forms complexes with nidogen, a sulphated glycoprotein [58], in specialised basement membranes [59]. In general, changes in basement membrane composition facilitate pathological mechanisms [60]. In addition, annexins play a central role in maintenance of cytoskeleton and extracellular matrix integrity [61], as well as $\mathrm{Ca}^{2+}$ handling in the heart [62]. A previous analysis of annexin in dystrophin-deficient skeletal muscles has indicated that certain annexin isoforms are gradually released from the sarcolemmal membrane into the cytosol and into the extracellular space during the progression of dystrophinopathy [63]. In analogy, dystrophy-associated cardiomyopathy appears to 

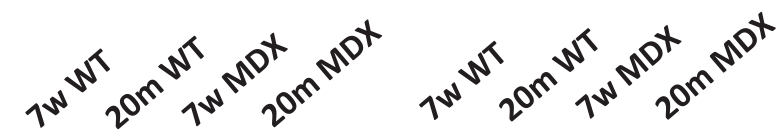

A PDH

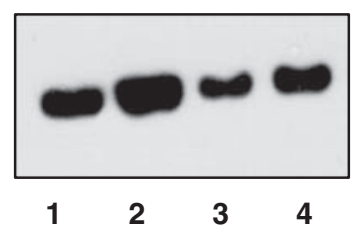

\section{B Aconitase}
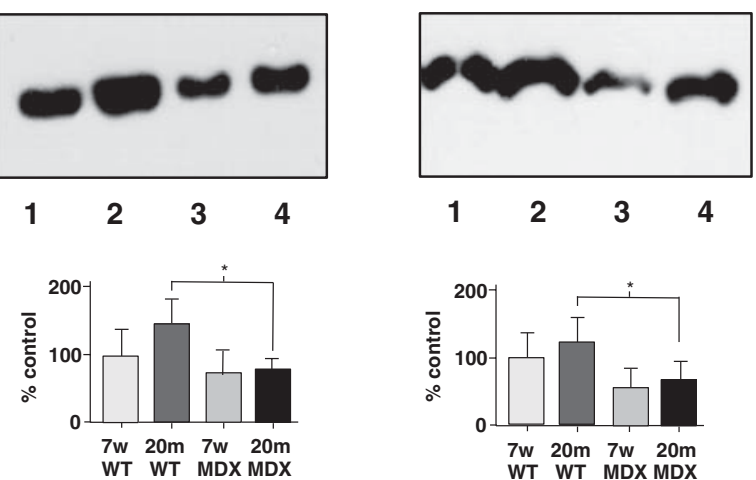

C MDH
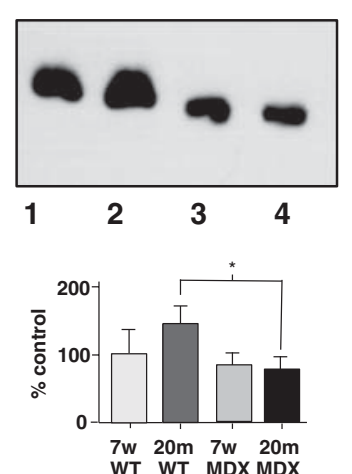

WT WT MDX MDX

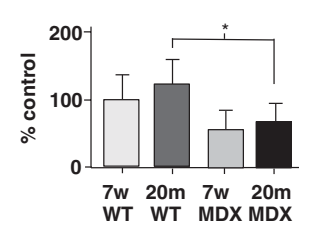

D VDAC1
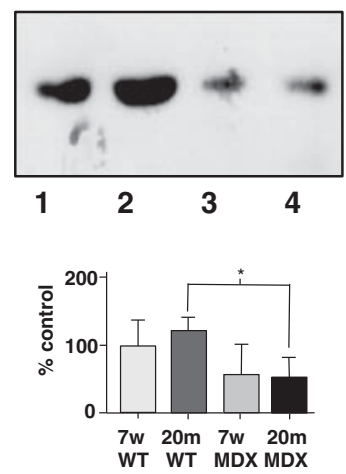

Figure 2. Immunoblot analysis of cardiac proteins in aging and dystrophic $m d x$ mice. Shown are representative immunoblots with expanded views of immuno-decorated bands (A-D). Immunoblotting was carried out with antibodies to pyruvate dehydrogenase $(A ; P D H)$, aconitase $(B)$, malate dehydrogenase $(C$; $\mathrm{MDH}$ ) and mitochondrial porin isoform VDAC1 (D). Lanes 1 to 4 represent normal 7-wk-old hearts, normal 20-month-old hearts, 7-wk-old $m d x$ hearts and 20-month-old $m d x$ hearts, respectively. Underneath individual immunolots are shown graphical presentation of the statistical evaluation of immuno-decorations. The comparative blotting between 7-wk-old $m d x$ hearts and 20-month-old $m d x$ hearts was statistically evaluated using an unpaired Student's $t$-test $\left(n=5 ;{ }^{*} p<0.05\right)$. The concentration of pyruvate dehydrogenase, aconitase, malate dehydrogenase and VDAC1 was found to be significantly different between young and old $m d x$ hearts.

be also characterised by a drastic reduction in annexin - which in turn might be responsible for the decreased levels of the cytoskeletal protein vimentin. While the natural aging process is associated with an increased density of cardiac laminin, nidogen and annexin, muscular dystrophy triggers a severe reduction in these structural heart proteins. Thus, the deficiency in cardiac dystrophin seems to have a major desta- bilising effect on the fibre periphery and its linkage to the extracellular matrix and cytoskeleton. These molecular and cellular changes are probably key events that cause cardiomyopathic complications and might explain the severe clinical phenotype of the heart in dystrophinopathy [6]. In addition, the age-dependent decrease in the nuclear protein lamin in the dystrophic $m d x$ heart might destabilise nuclear integrity, transcriptional control and chromatin organisation [64], as well as trigger premature aging in the dystrophin-deficient heart [65].

The label-free LC-MS analysis of the aged $m d x$ heart has identified disturbed levels of a variety of mitochondrial proteins and a general trend of increased glycolytic enzymes. This suggests considerable metabolic changes and potential adaptations in dystrophin-deficient heart tissue. Increased mitochondrial enzymes included isocitrate dehydrogenase, creatine kinase, isovaleryl-CoA dehydrogenase, aldehyde dehydrogenase and long-chain specific acyl-CoA dehydrogenase. In contrast, reduced levels were established for the mitochondrial proteins ATP synthase, NADH dehydrogenase, succinate dehydrogenase, cytochrome b-c1 complex, cytochrome c oxidase, succinyl-CoA ligase and long-chain fatty acid CoA ligase. The reduction in key components of the mitochondrial electron transport chain suggests impaired oxidative phosphorylation. Lower levels of the mitochondrial complex V enzyme ATP synthase, which plays a central role in the biochemical generation of ATP, would agree with a reduced ATP production in $m d x$ hearts [66]. A reduction in critical elements of cardiac mitochondria would contribute in a major way to a bioenergetic crisis in dystrophin-deficient tissue, as previously suggested by a gel electrophoresis-based proteomic study of the $m d x$ heart [16]. It has long been established that impaired mitochondrial metabolism plays an important pathogenic feature in dystrophinopathy. Mitochondria from $m d x$ skeletal muscle were shown to exhibit significant uncoupling of oxidative phosphorylation and a reduction in maximal ATP synthesis capacity, which results in decreased intramuscular ATP levels [67]. A recent study by Percival and co-workers [68] has shown that the lack of the membrane cytoskeletal protein dystrophin disrupts the subsarcolemmal localisation of mitochondria, promotes mitochondrial inefficiency and restricts maximal mitochondrial ATP-generating capacity. The proteomic analysis of the aged $m d x$ heart presented here agrees with this idea of a bioenergetic dysfunction of mitochondria and suggests that the inability of $m d x$ heart mitochondria to meet ATP demand increases during aging. The observed increased expression of glycolysis-associated enzymes could be interpreted as a compensatory mechanism to stabilise ATP levels. Thus, the increase in phosphoglycerate mutase, aldolase, glucose-6phosphate isomerase, triosephosphate isomerase and lactate dehydrogenase might be a natural mechanism to counteract the pathophysiological loss of mitochondrial ATP production and at least partially balance the metabolic need for ATP in the dystrophic heart. This would suggest a general tendency to an oxidative-to-glycolytic shift in cardiac $m d x$ metabolism. 
Based on the previous finding that dystrophin deficiency causes a drastic decrease in the dystrophin-connected $\alpha / \beta$ dystroglycan complex in the $m d x$ heart [30], we could show here that additional secondary changes appear to trigger the loss in key extracellular matrix linker proteins. Alterations down-stream from the direct binding partners of the dystrophin complex have previously been established, including lower levels of the sarcoplasmic reticulum $\mathrm{Ca}^{2+}$-buffering proteins sarcalumenin and calsequestrin in the membrane fraction from dystrophic hearts [32]. In addition, here we could show by label-free LC-MS/MS analysis that secondary effects influence the concentration of ferritin, tranferrin, catalase, GSH transferase, laminin, nidogen and annexin, as well as a large number of enzymes involved in both anaerobic and oxidative metabolism. Aging of the $m d x$ heart appears to have a profound influence on many structural proteins and metabolic enzymes. Ion transportation, the cellular stress response, ion handling and the maintenance of the contractile apparatus seem to be affected in dystrophindeficient heart muscle. Dystrophinopathy-associated changes in a broad range of cardiac proteins supports the idea of severe pathobiochemical complications in aged $m d x$ mice and establishes this genetic model as a suitable system to evaluate new drug treatments to counteract cardiomyopathy.

Research was supported by a project grant from Muscular Dystrophy Ireland to K.O. and a postgraduate stipend by the PRTLI5 BioAT programme of the Irish Higher Education Authority to A.H.

The authors have declared no conflict of interest.

\section{References}

[1] Dalkilic, I., Kunkel, L. M., Muscular dystrophies: genes to pathogenesis. Curr. Opin. Genet. Dev. 2003, 13, 231-238.

[2] Lewis, C., Carberry, S., Ohlendieck, K., Proteomic profiling of x-linked muscular dystrophy. J. Muscle Res. Cell. Motil. 2009, 30, 267-279.

[3] Morrison, L. A., Dystrophinopathies. Handb. Clin. Neurol. 2011, 101, 11-39.

[4] Hermans, M. C., Pinto, Y. M., Merkies, I. S., de Die-Smulders, C. E. et al., Hereditary muscular dystrophies and the heart. Neuromuscul. Disord. 2010, 20, 479-492.

[5] Verhaert, D., Richards, K., Rafael-Fortney, J. A., Raman, S. V., Cardiac involvement in patients with muscular dystrophies: magnetic resonance imaging phenotype and genotypic considerations. Circ. Cardiovasc. Imaging. 2011, 4, 67-76.

[6] Judge, D. P., Kass, D. A., Thompson, W. R., Wagner, K. R., Pathophysiology and therapy of cardiac dysfunction in Duchenne muscular dystrophy. Am. J. Cardiovasc. Drugs. 2011, 11, 287-294.

[7] Romfh, A., McNally, E. M., Cardiac assessment in Duchenne and Becker muscular dystrophies. Curr. Heart Fail Rep. 2010, 7, 212-218.
[8] Kaspar, R. W., Allen, H. D., Montanaro, F., Current understanding and management of dilated cardiomyopathy in Duchenne and Becker muscular dystrophy. J. Am. Acad. Nurse Pract. 2009, 21, 241-249.

[9] Cox, G. F., Kunkel, L. M., Dystrophies and heart disease. Curr. Opin. Cardiol. 1997, 12, 329-343.

[10] Finsterer, J., Stöllberger, C., The heart in human dystrophinopathies. Cardiology 2003, 99, 1-19.

[11] Gardan-Salmon, D., Dixon, J. M., Lonergan, S.M., Selsby, J.T., Proteomic assessment of the acute phase of dystrophin deficiency in mdx mice. Eur. J. Appl. Physiol. 2011, 111, 2763-2773.

[12] Rayavarapu, S., Coley, W., Cakir, E., Jahnke, V. et al., Identification of disease specific pathways using in vivo SILAC proteomics in dystrophin deficient mdx mouse. Mol. Cell. Proteomics 2013, 12, 1061-1073.

[13] Sicinski, P., Geng, Y., Ryder-Cook, A. S., Barnard, E. A. et al., The molecular basis of muscular dystrophy in the $\mathrm{mdx}$ mouse: a point mutation. Science 1989, 244, 1578-1580.

[14] Johnson, E. K., Zhang, L., Adams, M. E., Phillips, A. et al., Proteomic analysis reveals new cardiac-specific dystrophinassociated proteins. PLoS One 2012, 7, e43515.

[15] Gulston, M. K., Rubtsov, D. V., Atherton, H. J., Clarke, K. et al., A combined metabolomic and proteomic investigation of the effects of a failure to express dystrophin in the mouse heart. J. Proteome Res. 2008, 7, 2069-2077.

[16] Lewis, C., Jockusch, H., Ohlendieck, K., Proteomic profiling of the dystrophin-deficient $\mathrm{mdx}$ heart reveals drastically altered levels of key metabolic and contractile proteins. J. Biomed. Biotechnol. 2010, 2010, 648501.

[17] Shioi, T., Inuzuka, Y., Aging as a substrate of heart failure. J. Cardiol. 2012, 60, 423-428.

[18] Richardson, M. R., Lai, X., Mason, S. B., Miller, S. J. et al., Differential protein expression during aging in ventricular myocardium of Fischer 344 x Brown Norway hybrid rats. Exp. Gerontol. 2008, 43, 909-918.

[19] Dai, Q., Escobar, G. P., Hakala, K. W., Lambert, J. M. et al., The left ventricle proteome differentiates middle-aged and old left ventricles in mice. J. Proteome Res. 2008, 7, 756-765.

[20] Grant, J. E., Bradshaw, A. D., Schwacke, J. H., Baicu, C. F. et al., Quantification of protein expression changes in the aging left ventricle of Rattus norvegicus. J. Proteome Res. 2009, 8, 4252-4263.

[21] Carberry, S., Zweyer, M., Swandulla, D., Ohlendieck, K., Proteomics reveals drastic increase of extracellular matrix proteins collagen and dermatopontin in the aged $\mathrm{mdx}$ diaphragm model of Duchenne muscular dystrophy. Int. J. Mol. Med. 2012, 30, 229-234.

[22] Doran, P., Martin, G., Dowling, P., Jockusch, H., Ohlendieck, K., Proteome analysis of the dystrophin-deficient MDX diaphragm reveals a drastic increase in the heat shock protein cvHSP. Proteomics 2006, 6, 4610-4621.

[23] Meleady, P., Gallagher, M., Clarke, C., Henry, M. et al., Impact of miR-7 over-expression on the proteome of Chinese hamster ovary cells. J. Biotechnol. 2012, 160, 251-262. 
[24] Meleady, P., Hoffrogge, R., Henry, M., Rupp, O. et al. Utilization and evaluation of $\mathrm{CHO}$-specific sequence databases for mass spectrometry based proteomics. Biotechnol. Bioeng. 2012, 109, 1386-1394.

[25] O'Connell, K., Ohlendieck, K., Proteomic DIGE analysis of the mitochondria-enriched fraction from aged rat skeletal muscle. Proteomics 2009, 9, 5509-5524.

[26] Partridge, T. A., Impending therapies for Duchenne muscular dystrophy. Curr. Opin. Neurol. 2011, 24, 415-422.

[27] Ameen, V., Robson, L. G., Experimental models of Duchenne muscular dystrophy: relationship with cardiovascular disease. Open Cardiovasc. Med. J. 2010, 4, 265-77.

[28] De Luca, A., Pre-clinical drug tests in the mdx mouse as a model of dystrophinopathies: an overview. Acta Myol. 2012, $31,40-47$.

[29] Durbeej, M., Campbell, K. P., Muscular dystrophies involving the dystrophin-glycoprotein complex: an overview of current mouse models. Curr. Opin. Genet. Dev. 2002, 12, 349-361.

[30] Bia, B. L., Cassidy, P. J., Young, M. E., Rafael, J. A. et al., Decreased myocardial nNOS, increased iNOS and abnormal ECGs in mouse models of Duchenne muscular dystrophy. $J$. Mol. Cell. Cardiol. 1999, 31, 1857-1862.

[31] Lohan, J., Culligan, K., Ohlendieck, K., Deficiency in cardiac dystrophin affects the abundance of the alpha/betadystroglycan complex. J. Biomed. Biotechnol. 2005, 2005, 28-36.

[32] Lohan, J., Ohlendieck, K., Drastic reduction in the luminal $\mathrm{Ca}^{2+}$-binding proteins calsequestrin and sarcalumenin in dystrophin-deficient cardiac muscle. Biochim. Biophys. Acta. 2004, 1689, 252-258.

[33] Jung, C., Martins, A. S., Niggli, E., Shirokova, N., Dystrophic cardiomyopathy: amplification of cellular damage by $\mathrm{Ca}^{2+}$ signalling and reactive oxygen species-generating pathways. Cardiovasc. Res. 2008, 77, 766-773.

[34] Fanchaouy, M., Polakova, E., Jung, C., Ogrodnik, J. et al., Pathways of abnormal stress-induced $\mathrm{Ca}^{2+}$ influx into dystrophic mdx cardiomyocytes. Cell Calcium 2009, 46, 114-121.

[35] Au, C. G., Butler, T. L., Sherwood, M. C., Egan, J. R. et al., Increased connective tissue growth factor associated with cardiac fibrosis in the mdx mouse model of dystrophic cardiomyopathy. Int. J. Exp. Pathol. 2011, 92, 57-65.

[36] Koenig, X., Dysek, S., Kimbacher, S., Mike, A. K. et al., Voltage-gated ion channel dysfunction precedes cardiomyopathy development in the dystrophic heart. PLoS One 2011 6 , e20300.

[37] Barnabei, M. S., Metzgerm, J. M., Ex vivo stretch reveals altered mechanical properties of isolated dystrophin-deficient hearts. PLoS One 2012, 7, e32880.

[38] Stuckey, D. J., Carr, C. A., Camelliti, P., Tyler, D. J. et al., In vivo $\mathrm{MRI}$ characterization of progressive cardiac dysfunction in the mdx mouse model of muscular dystrophy. PLoS One 2012, 7, e28569.

[39] Quinlan, J. G., Hahn, H. S., Wong, B. L., Lorenz, S. N. et al., Evolution of the $\mathrm{mdx}$ mouse cardiomyopathy: physiological and morphological findings. Neuromuscul. Disord. 2004, 14, $491-496$.
[40] Spurney, C. F., Knoblach, S., Pistilli, E. E., Nagaraju, K. et al., Dystrophin-deficient cardiomyopathy in mouse: expression of Nox4 and Lox are associated with fibrosis and altered functional parameters in the heart. Neuromuscul. Disord. 2008, 18, 371-381.

[41] Van Erp, C., Loch, D., Laws, N., Trebbin, A. et al., Timeline of cardiac dystrophy in 3-18-month-old MDX mice. Muscle Nerve 2010, 42, 504-513.

[42] Klietsch, R., Ervasti, J. M., Arnold, W., Campbell, K. P. et al., Dystrophin-glycoprotein complex and laminin colocalize to the sarcolemma and transverse tubules of cardiac muscle. Circ. Res. 1993, 72, 349-360.

[43] Zhao, P., Sharma, A. C., Ren, J., Pathogenesis and therapy of autoimmunity-induced dilated cardiomyopathy. Front. Biosci. 2009, 14, 1708-1715.

[44] Szőke, D., Panteghini, M., Diagnostic value of transferrin. Clin. Chim. Acta. 2012, 413, 1184-1189.

[45] Wang, J., Pantopoulos, K., Regulation of cellular iron metabolism. Biochem. J. 2011, 434, 365-381.

[46] Crichton, R. R., Declercq, J. P., X-ray structures of ferritins and related proteins. Biochim. Biophys. Acta 2010, 1800, 706-718.

[47] Harrison, P. M., Arosio, P., The ferritins: molecular properties, iron storage function and cellular regulation. Biochim. Biophys. Acta 1996, 1275, 161-203.

[48] Board, P. G., Menon, D., Glutathione transferases, regulators of cellular metabolism and physiology. Biochim. Biophys. Acta. 2013, 1830, 3267-3288.

[49] Dulhunty, A. F., Hewawasam, R., Liu, D., Casarotto, M. G. et al., Regulation of the cardiac muscle ryanodine receptor by glutathione transferases. Drug Metab. Rev. 2011, 43, 236-252.

[50] Haycock, J. W., MacNeil, S., Jones, P., Harris, J. B. et al., Oxidative damage to muscle protein in Duchenne muscular dystrophy. Neuroreport 1996, 8, 357-361.

[51] Hauser, E., Höger, H., Bittner, R., Widhalm, K. et al., Oxyradical damage and mitochondrial enzyme activities in the $\mathrm{mdx}$ mouse. Neuropediatrics 1995, 26, 260-272.

[52] Renjini, R., Gayathri, N., Nalini, A., Srinivas Bharath, M. M. Oxidative damage in muscular dystrophy correlates with the severity of the pathology: role of glutathione metabolism. Neurochem. Res. 2012, 37, 885-898.

[53] Tidball, J. G., Wehling-Henricks, M., The role of free radicals in the pathophysiology of muscular dystrophy. J. Appl. Physiol. 2007, 102, 1677-1686.

[54] Williams, I.A., Allen, D. G., The role of reactive oxygen species in the hearts of dystrophin-deficient mdx mice. Am. J. Physiol. Heart. Circ. Physiol. 2007, 293, H1969-H1977.

[55] Selsby, J. T., Increased catalase expression improves muscle function in mdx mice. Exp. Physiol. 2011, 96, 194-202.

[56] Domogatskaya, A., Rodin, S., Tryggvason, K., Functional diversity of laminins. Annu. Rev. Cell Dev. Biol. 2012, 28, 523-553.

[57] Carmignac, V., Durbeej, M., Cell-matrix interactions in muscle disease. J. Pathol. 2012, 226, 200-218. 
[58] Dziadek, M., Role of laminin-nidogen complexes in basement membrane formation during embryonic development. Experientia 1995, 51, 901-913.

[59] Ho, M.S., Böse, K., Mokkapati, S., Nischt, R. et al., Nidogensextracellular matrix linker molecules. Microsc. Res. Tech. 2008, 71, 387-395.

[60] Kruegel, J., Miosge, N., Basement membrane components are key players in specialized extracellular matrices. Cell. Mol. Life Sci. 2010, 67, 2879-2895.

[61] Bizzarro, V., Petrella, A., Parente, L., Annexin A1: novel roles in skeletal muscle biology. J. Cell Physiol. 2012, 227, 3007-3015.

[62] Camors, E., Monceau, V., Charlemagne, D., Annexins and $\mathrm{Ca}^{2+}$ handling in the heart. Cardiovasc. Res. 2005, 65, 793-802.

[63] Selbert, S., Fischer, P., Menke, A., Jockusch, H. et al., Annexin VII relocalization as a result of dystrophin deficiency. Exp. Cell Res. 1996, 222, 199-208.
[64] Broers, J. L., Ramaekers, F. C., Bonne, G., Yaou, R. B. et al., Nuclear lamins: laminopathies and their role in premature ageing. Physiol. Rev. 2006, 86, 967-1008.

[65] Reddy, S., Comai, L., Lamin A, farnesylation and aging. Exp. Cell Res. 2012, 318, 1-7.

[66] Zhang, W., ten Hove, M., Schneider, J. E., Stuckey, D. J. et al., Abnormal cardiac morphology, function and energy metabolism in the dystrophic mdx mouse: an MRI and MRS study. J. Mol. Cell. Cardiol. 2008, 45, 754-760.

[67] Kuznetsov, A. V., Winkler, K., Wiedemann, F. R., von Bossanyi, P. et al., Impaired mitochondrial oxidative phosphorylation in skeletal muscle of the dystrophin-deficient $\mathrm{mdx}$ mouse. Mol. Cell. Biochem. 1998, 183, 87-96.

[68] Percival, J. M., Siegel, M. P., Knowels, G., Marcinek, D. J., Defects in mitochondrial localization and ATP synthesis in the mdx mouse model of Duchenne muscular dystrophy are not alleviated by PDE5 inhibition. Hum. Mol. Genet. 2013, 22, 153-167. 